\title{
Luteibacter anthropi sp. nov., isolated from human blood, and reclassification of Dyella yeojuensis Kim et al. 2006 as Luteibacter yeojuensis comb. nov.
}

\author{
Correspondence \\ Peter Kämpfer \\ peter.kaempfer@umwelt.uni- \\ giessen.de
}

\author{
Peter Kämpfer, ${ }^{1}$ Nicole Lodders ${ }^{1}$ and Enevold Falsen ${ }^{2}$ \\ ${ }^{1}$ Institut für Angewandte Mikrobiologie, Justus-Liebig-Universität Giessen, D-35392 Giessen, \\ Germany \\ ${ }^{2}$ Culture Collection University Göteborg, Department of Clinical Bacteriology, S-41346 Göteborg, \\ Sweden
}

\begin{abstract}
A yellow-pigmented bacterium was isolated from blood of a 3-year-old boy in Göteborg, Sweden. Comparative analysis of 16S rRNA gene sequences showed that this bacterium is most closely related to Luteibacter rhizovicinus $\mathrm{LJ} 6^{\top}$ and Dyella yeojuensis R2A16-10 ${ }^{\top}$, with sequence similarity of $98.3 \%$ to both. Strain CCUG $25036^{\top}$ is clearly different from L. rhizovicinus CCUG $50033^{\top}$ and also from $D$. yeojuensis DSM $17673^{\top}$ in that DNA-DNA hybridization revealed relatedness of 33.7 and $29.8 \%$, respectively. Strain CCUG $25036^{\top}$ is further distinguished from L. rhizovicinus CCUG $50033^{\top}$ and D. yeojuensis DSM $17673^{\top}$ by being able to use D-mannose, D-mannitol and gluconate as sole carbon sources and by lacking the ability to use maltose or sucrose as sole carbon sources. The name Luteibacter anthropi sp. nov. is proposed for this novel species, with the type strain CCUG $25036^{\top}\left(=\mathrm{CCM} 7598^{\top}\right)$. The proposal is also made to reclassify Dyella yeojuensis as Luteibacter yeojuensis comb. nov., with the type strain R2A16-10 $\left(=\right.$ DSM $17673^{\top}=$ KACC $\left.11405^{\top}\right)$.
\end{abstract}

Since the description of Luteibacter rhizovicinus (Johansen et al., 2005), no additional members of the genus Luteibacter have been described. Members of the genus are characterized as Gram-negative rods, showing aerobic growth and producing yellow-pigmented colonies, with membranes showing a fatty acid composition consisting largely of branched compounds (mainly iso- $\mathrm{C}_{15: 0}$, iso$\mathrm{C}_{17: 1} \omega 9 c$ and iso- $\mathrm{C}_{17: 0}$ ) (Johansen et al., 2005). Here, we describe strain CCUG $25036^{\mathrm{T}}$, a new member of this genus. Furthermore, we propose the reclassification of Dyella yeojuensis Kim et al. 2006 into the genus Luteibacter.

Strain CCUG $25036^{\mathrm{T}}$ was isolated from the blood of a 3year-old boy in Göteborg, Sweden. Colonies of CCUG $25036^{\mathrm{T}}$ grown on tryptone soy agar (TSA; Oxoid) are yellow, circular and low-convex with entire margins and a smooth appearance. Phenotypic properties of strain CCUG $25036^{\mathrm{T}}$ compared with L. rhizovicinus CCUG $50033^{\mathrm{T}}$ are shown in Table 1. Cell morphology was observed under a Zeiss light microscope at $\times 1000$, with cells grown for 3 days at $28{ }^{\circ} \mathrm{C}$ on TSA. Cells of CCUG $25036^{\mathrm{T}}$ were thin rods, 3-4 $\mu \mathrm{m}$ long and 1-2 $\mu \mathrm{m}$ wide. Cells were motile. The ranges of temperature and $\mathrm{pH}$ for growth of strain CCUG $25036^{\mathrm{T}}$ were determined by examining growth on TSA. To determine the temperature range, TSA plates were

The GenBank/EMBL/DDBJ accession number for the 16S rRNA gene sequence of strain CCUG $25036^{\top}$ is $\mathrm{FM} 212561$. incubated at $8,15,20,25,28,36,37,38,45$ and $55^{\circ} \mathrm{C}$. Growth of L. rhizovicinus CCUG $50033^{\mathrm{T}}$ was tested in parallel with strain CCUG $25036^{\mathrm{T}}$. Growth was observed from 20 to $38{ }^{\circ} \mathrm{C}$, but not at or below $15^{\circ} \mathrm{C}$ or at $45^{\circ} \mathrm{C}$ or above. In contrast, growth of L. rhizovicinus CCUG $50033^{\mathrm{T}}$ was observed only at $15,20,25$ and $28{ }^{\circ} \mathrm{C}$, and not at 8 or $36{ }^{\circ} \mathrm{C}$ or above. To determine the $\mathrm{pH}$ range, tryptone soy broth was buffered to various $\mathrm{pH}$ values and growth at each $\mathrm{pH}$ was monitored spectrophotometrically at $600 \mathrm{~nm}$. Growth was observed within a $\mathrm{pH}$ range of 4.5 to 9.5 , but not at $\mathrm{pH} 10.5$.

The 16S rRNA gene was analysed as described by Kämpfer et al. (2003). DNA extraction was carried out using the GenElute Plant Genomic DNA kit (Sigma-Aldrich) according to the manufacturer's instructions. The $16 \mathrm{~S}$ rRNA gene was amplified by PCR using the primer pair 27F (5'-GAGTTTGATCMTGGCTCAG-3') and MR 1492R (5'-ACGGYTACCTTGTTACGACTT-3') (Lane, 1991) and the following cycle conditions: $95{ }^{\circ} \mathrm{C}$ for $3 \mathrm{~min}, 28$ cycles of $94{ }^{\circ} \mathrm{C}$ for $1 \mathrm{~min}, 57.3{ }^{\circ} \mathrm{C}$ for $45 \mathrm{~s}$ and $72{ }^{\circ} \mathrm{C}$ for $2 \mathrm{~min}$ and a final step at $72{ }^{\circ} \mathrm{C}$ for $15 \mathrm{~min}$. The PCR product was purified with the QIAquick PCR purification kit (Qiagen) according to the manufacturer's instructions and was sequenced by a sequencing service (Institute of Microbiology and Molecular Biology, Justus-LiebigUniversität Giessen, Giessen, Germany) with standard sequencing primers for the 16S rRNA gene. Phylogenetic 
Table 1. Comparison of characteristics of the type strains of Luteibacter species

Strains: 1, CCUG $25036^{\mathrm{T}}$; 2, L. rhizovicinus CCUG 50033 ${ }^{\mathrm{T}}$; 3, L. (Dyella) yeojuensis DSM $17673^{\mathrm{T}}$. All three strains are positive for utilization of Dglucose and hydrolysis of aesculin, $o$-nitrophenyl $\beta$-D-galactopyranoside, bis-p-nitrophenyl (pNP) phosphate and $\mathrm{pNP} \alpha$-D-glucopyranoside. All three strains are negative for utilization of L-arabinose, D-gluconate, adipate, citrate, lactate and phenylacetate. Results for the utilization of $\mathrm{L}$ arabinose, D-gluconate, adipate, citrate, $\mathrm{N}$-acetyl-D-glucosamine, Dmannitol, maltose, DL-malate and phenylacetate and for acid formation from D-glucose were confirmed with the API $20 \mathrm{NE}$ system. On the basis of the tests of the API $20 \mathrm{NE}$ system, strain CCUG $25036^{\mathrm{T}}$ and $L$. rhizovicinus CCUG $50033^{\mathrm{T}}$ are negative for utilization of caprate, tryptophan deaminase, arginine dihydrolase, urease and reduction of nitrate. All three strains grow on MacConkey agar and on TSA at $28{ }^{\circ} \mathrm{C}$. + , Positive; $(+)$, weakly positive; - , negative.

\begin{tabular}{|lccc|}
\hline Characteristic & $\mathbf{1}$ & $\mathbf{2}$ & $\mathbf{3}$ \\
\hline Carbon sources utilized & & & \\
N-Acetyl-D-glucosamine & + & - & + \\
Trehalose & - & + & + \\
D-Mannitol & + & - & - \\
Maltose & + & - & + \\
Sucrose & - & + & + \\
D-Mannose & + & - & + \\
DL-Malate & + & - & - \\
Acid formation from D-glucose & $(+)$ & - & - \\
\end{tabular}

analysis was performed using the ARB software package (version December 2007; Ludwig et al., 2004) and the corresponding SILVA SSURef 95 database (version July 2008; Pruesse et al., 2007). Trees were reconstructed using the maximum-likelihood method with fastDNAml (Olsen et al., 1994) and $50 \%$ as well as $30 \%$ conservation filters (only alignment columns in which the frequency of the most abundant nucleotide is equal to or more than 50 and $30 \%$, respectively, are included in the calculation). Tree topology was further tested without filters. No significant differences could be detected between these trees. Trees reconstructed with the neighbour-joining and maximumparsimony methods showed similar results (data not shown).

The almost-complete 16S rRNA gene sequence (1419 bp) of the strain was compared by sequence similarity calculations. The results of these calculations indicated that the closest relatives of strain CCUG $25036^{\mathrm{T}}$ were $L$. rhizovicinus LG96 $^{\mathrm{T}}(98.3 \%$ similarity $), \quad$ D. yeojuensis $\mathrm{R} 2 \mathrm{~A} 16-10^{\mathrm{T}}(98.3 \%)$ and Dyella koreensis $\mathrm{BB}^{\mathrm{T}}(96.4 \%)$. A maximum-likelihood tree is shown in Fig. 1. The strong relationship with $D$. yeojuensis is obvious, and the branching pattern of CCUG $25036^{\mathrm{T}}$ and its nearest relatives, including the type strain of $D$. yeojuensis, was confirmed by neighbour-joining and maximum-parsimony analyses, with L. rhizovicinus as the closest relative (data not shown). For this reason, we included D. yeojuensis DSM $17673^{\mathrm{T}}$ in our further comparative studies.

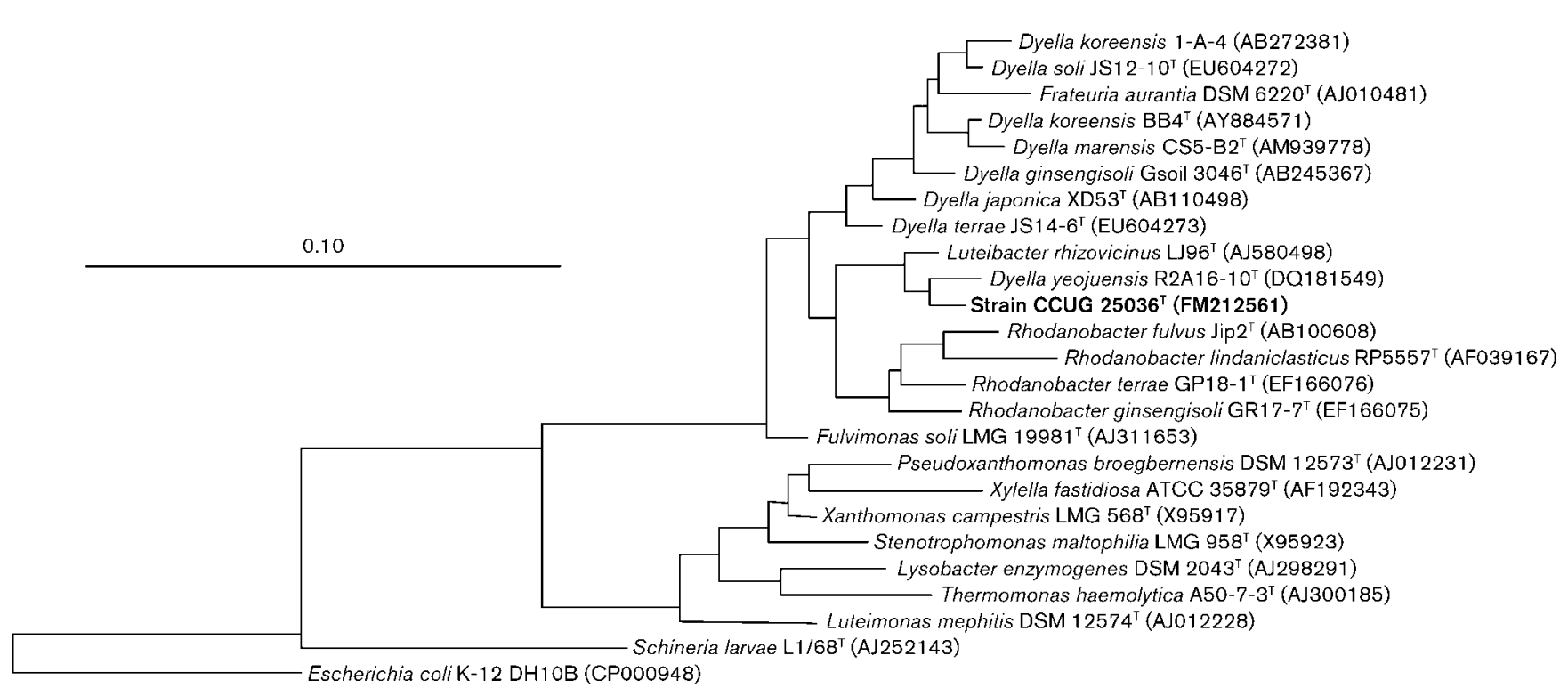

Fig. 1. Phylogenetic analysis based on $16 \mathrm{~S}$ rRNA gene sequences available from the EMBL database (accession numbers in parentheses). The phylogenetic tree was constructed using the ARB software package (version December 2007; Ludwig et al., 2004) and the corresponding SILVA SSURef 95 database (version July 2008; Pruesse et al., 2007). Tree building was performed using the maximum-likelihood method with fastDNAml (Olsen et al., 1994) and no conservation filter. Bar, 0.10 substitutions per nucleotide position. 
The other members of the genus Dyella, including the most recently described species Dyella ginsengisoli (Jung et al., 2009), D. marensis (Lee \& Lee, 2009), D. soli and D. terrae (Weon et al., 2009), and the members of the genera Luteibacter and Frateuria are also very similar in regard to phenotypic properties, and the combination of these genera may be justified on the basis of a more comprehensive dataset.

Carbon source utilization by strain CCUG $25036^{\mathrm{T}}$ was tested in comparison with L. rhizovicinus CCUG $50033^{\mathrm{T}}$ and $D$. yeojuensis DSM $17673^{\mathrm{T}}$ by inoculating the strains into microtitre plate wells as described by Kämpfer et al. (1991). In addition, strain CCUG $25036^{\mathrm{T}}$ and L. rhizovicinus CCUG $50033^{\mathrm{T}}$ were tested with the API $20 \mathrm{NE}$ system (bioMérieux), according to the instructions of the manufacturer. Compared with L. rhizovicinus CCUG $50033^{\mathrm{T}}$, strain CCUG $25036^{\mathrm{T}}$ differed in its abilities to use several sugars only after 5 days of incubation. Differences from D. yeojuensis DSM $17673^{\mathrm{T}}$ are also obvious, as detailed in Table 1.

Whole-cell fatty acid analysis was carried out using the MIDI protocol as described previously (Kämpfer \& Kroppenstedt, 1996). Cells were grown on TSA at $28{ }^{\circ} \mathrm{C}$ prior to fatty acid extraction according to the MIDI protocol. L. rhizovicinus CCUG $50033^{\mathrm{T}}$ and D. yeojuensis DSM $17673^{\mathrm{T}}$ were studied concurrently. Like L. rhizovicinus CCUG $50033^{\mathrm{T}}$, strain CCUG $25036^{\mathrm{T}}$ has large proportions of branched compounds (mainly iso- $\mathrm{C}_{15: 0}$, iso- $\mathrm{C}_{17: 1} \omega 9 c$ and iso- $\mathrm{C}_{17: 0}$ ), which is in congruence with the findings of Johansen et al. (2005). The fatty acid profile of D. yeojuensis DSM $17673^{\mathrm{T}}$ was also very similar to those of the other two strains; however, some (mainly quantitative) differences could be observed. The fatty acid patterns of the three strains are shown in Table 2.

To further clarify the relationship between these three strains, DNA-DNA hybridization experiments were performed using genomic DNA as described by Ziemke et al. (1998), except that, for nick translation, $2 \mu \mathrm{g}$ DNA was labelled during a $3 \mathrm{~h}$ incubation at $15{ }^{\circ} \mathrm{C}$. With this method, the reassociation value between strain CCUG $25036^{\mathrm{T}}$ and $L$. rhizovicinus CCUG $50033^{\mathrm{T}}$ was $33.7 \%$ (repetition $23.7 \%$ ). The reassociation value between strain CCUG $25036^{\mathrm{T}}$ and $D$. yeojuensis DSM $17673^{\mathrm{T}}$ was $29.8 \%$ (repetition $16.1 \%$ ). These values are well below the recommended threshold that is used to delineate species, confirming that strain CCUG $25036^{\mathrm{T}}$ represents a novel species.

On the basis of clear differences in the 16S rRNA gene sequence and the phenotype, we propose here a novel species of the genus Luteibacter, Luteibacter anthropi sp. nov. In addition, we propose the reclassification of Dyella yeojuensis as Luteibacter yeojuensis comb. nov. on the basis of our results.

\section{Description of Luteibacter anthropi sp. nov.}

Luteibacter anthropi (an.thro' pi. Gr. n. anthropos a human being; N.L. gen. n. anthropi of a human being, since the type strain was recovered from a human clinical specimen).
Table 2. Fatty acid profiles of the type strains of Luteibacter species

Strains: 1, CCUG $25036^{\mathrm{T}} ; 2$, L. rhizovicinus CCUG $50033^{\mathrm{T}} ; 3$, L. yeojuensis DSM $17673^{\mathrm{T}}$. Values are percentages of total fatty acids; - , not detected/not reported.

\begin{tabular}{|c|c|c|c|c|}
\hline \multirow[t]{2}{*}{ Fatty acid } & \multirow[t]{2}{*}{1} & \multirow[t]{2}{*}{2} & \multicolumn{2}{|c|}{3} \\
\hline & & & $\begin{array}{l}\text { This } \\
\text { study }\end{array}$ & $\begin{array}{c}\text { Kim et al. } \\
\quad(2006)\end{array}$ \\
\hline iso- $\mathrm{C}_{11: 0}$ & 3.6 & 4.0 & 3.8 & 3.7 \\
\hline Unknown 11.543 & - & 0.2 & - & - \\
\hline Unknown 11.799 & 0.8 & 2.2 & 1.9 & 2.3 \\
\hline iso- $\mathrm{C}_{11: 0} 3-\mathrm{OH}$ & 2.9 & 3.9 & 4.0 & 4.2 \\
\hline $\mathrm{C}_{12: 0}$ & - & 0.1 & - & - \\
\hline iso- $\mathrm{C}_{12: 0}$ & - & - & 0.3 & - \\
\hline iso- $\mathrm{C}_{13: 0}$ & 0.4 & 0.5 & - & - \\
\hline Unknown 13.565 & 1.8 & - & 0.4 & - \\
\hline $\mathrm{C}_{14: 0}$ & 0.5 & 0.4 & - & - \\
\hline iso- $\mathrm{C}_{14: 0}$ & - & - & 0.5 & 1.1 \\
\hline iso- $\mathrm{C}_{12: 0} 3-\mathrm{OH}$ & - & - & 1.0 & 1.0 \\
\hline iso- $\mathrm{C}_{13: 0} 3-\mathrm{OH}$ & 1.2 & 2.7 & 2.3 & 2.4 \\
\hline iso- $\mathrm{C}_{15: 0}$ & 21.7 & 17.0 & 9.2 & 14.5 \\
\hline anteiso- $\mathrm{C}_{15: 0}$ & 2.4 & 4.0 & 3.0 & 6.9 \\
\hline iso- $\mathrm{C}_{16: 0}$ & 0.5 & 0.8 & 18.6 & 21.3 \\
\hline Summed feature $3^{\star}$ & 6.5 & 9.2 & 4.3 & 5.2 \\
\hline $\mathrm{C}_{16: 0}$ & 5.6 & 6.5 & 1.4 & 1.8 \\
\hline iso- $\mathrm{C}_{16: 0} 3-\mathrm{OH}$ & - & - & 0.2 & - \\
\hline iso- $\mathrm{C}_{17: 1} \omega 9 c$ & 23.8 & 24.4 & 26.5 & 21.5 \\
\hline iso- $\mathrm{C}_{17: 0}$ & 27.0 & 22.4 & 14.9 & 7.9 \\
\hline anteiso- $\mathrm{C}_{17: 0}$ & 0.9 & 0.6 & 1.6 & 1.6 \\
\hline $\mathrm{C}_{18: 0}$ & 0.5 & - & - & - \\
\hline $\mathrm{C}_{17: 1} \omega 6 c$ & - & - & 1.8 & - \\
\hline $\mathrm{C}_{18: 1} \omega 7 c$ & - & 0.6 & - & - \\
\hline iso- $\mathrm{C}_{18: 0}$ & - & - & 2.2 & 1.2 \\
\hline iso- $\mathrm{C}_{17: 0} 3-\mathrm{OH}$ & - & 0.5 & 0.8 & - \\
\hline
\end{tabular}

${ }^{*}$ Summed feature 3 contains $\mathrm{C}_{16: 1} \omega 7 c$ and/or iso- $\mathrm{C}_{15: 0} 2-\mathrm{OH}$.

Cells are Gram-negative, motile rods, $2-4 \mu \mathrm{m}$ long. On TSA, colonies are yellow, circular and convex with a smooth appearance and entire margins. Growth occurs between 15 and $37{ }^{\circ} \mathrm{C}$; no growth is observed below $10{ }^{\circ} \mathrm{C}$ or above $38{ }^{\circ} \mathrm{C}$. The optimum temperature is $28{ }^{\circ} \mathrm{C}$. Growth occurs at $\mathrm{pH} 4.5-9.5$, but not at $\mathrm{pH} 10.5$. Optimum growth at $\mathrm{pH}$ 7.0. Aerobic and positive for oxidase, but negative for catalase. The major membrane fatty acids are iso- $\mathrm{C}_{15: 0}$, iso- $\mathrm{C}_{17: 1} \omega 9 \mathrm{c}$ and iso- $\mathrm{C}_{17: 0}$. Minor fatty acids are $\mathrm{C}_{16: 0}$, iso- $\mathrm{C}_{11: 0} 3-\mathrm{OH}$, iso- $\mathrm{C}_{13: 0} 3-\mathrm{OH}$, anteiso- $\mathrm{C}_{15: 0}$, anteiso $\mathrm{C}_{17: 0}$ and summed feature 3 $\left(\mathrm{C}_{16: 1} \omega 7 c\right.$ and/or iso- $\left.\mathrm{C}_{15: 0} 2-\mathrm{OH}\right)$. Uses the following as sole carbon sources: D-glucose, $\mathrm{N}$-acetyl-D-glucosamine, Dmannitol, D-mannose, gluconate and DL-malate. Cannot use the following carbon sources: D-ribose, D-fructose, sucrose, L-glutamate, L-cysteine, DL-aspartate, citrate, pyruvate, acetate, $N$-acetylgalactosamine, cellobiose, 
DL-lactate, salicin and D-xylose. Not able to hydrolyse starch or gelatin.

The type and only strain, CCUG $25036^{\mathrm{T}}\left(=\mathrm{CCM} 7598^{\mathrm{T}}\right)$, was isolated from the blood of a 3 -year-old boy in Göteborg, Sweden.

\section{Description of Luteibacter yeojuensis comb. nov.}

Luteibacter yeojuensis (yeo.ju.en'sis. N.L. masc. adj. yeojuensis pertaining to Yeoju, a city in Korea, from where the type strain originated).

Basonym: Dyella yeojuensis Kim et al. 2006.

The description is as given for Dyella yeojuensis by Kim et al. (2006). In addition, the following carbon sources can be utilized: D-glucose, $\mathrm{N}$-acetyl-D-glucosamine, arbutin, cellobiose, D-fructose, D-galactose, maltose, D-mannose, Dribose, sucrose (weak), trehalose, D-xylose, acetate and pyruvate. Cannot use the following carbon sources: gluconate, DL-malate, L-glutamate, L-cysteine, DL-aspartate, citrate, pyruvate, $\mathrm{N}$-acetylgalactosamine, DL-lactate and salicin.

The type strain is R2A16- $10^{\mathrm{T}}\left(=\mathrm{KACC} 11405^{\mathrm{T}}=\mathrm{DSM}\right.$ $\left.17673^{\mathrm{T}}\right)$.

\section{References}

Johansen, J. E., Binnerup, S. J., Kroer, N. \& Mølbak, L. (2005). Luteibacter rhizovicinus gen. nov., sp. nov., a yellow-pigmented gammaproteobacterium isolated from the rhizosphere of barley (Hordeum vulgare L.). Int J Syst Evol Microbiol 55, 2285-2291.

Jung, H.-M., Ten, L. N., Kim, K.-H., An, D. S., Im, W.-T. \& Lee, S.-T. (2009). Dyella ginsengisoli sp. nov., isolated from soil of a ginseng field in South Korea. Int J Syst Evol Microbiol 59, 460-465.
Kämpfer, P. \& Kroppenstedt, R. M. (1996). Numerical analysis of fatty acid patterns of coryneform bacteria and related taxa. Can J Microbiol 42, 989-1005.

Kämpfer, P., Steiof, M. \& Dott, W. (1991). Microbiological characterisation of a fuel-oil contaminated site including numerical identification of heterotrophic water and soil bacteria. Microb Ecol 21, 227-251.

Kämpfer, P., Dreyer, U., Neef, A., Dott, W. \& Busse, H.-J. (2003). Chryseobacterium defluvii sp. nov., isolated from wastewater. Int J Syst Evol Microbiol 53, 93-97.

Kim, B.-Y., Weon, H.-Y., Lee, K.-H., Seok, S.-J., Kwon, S.-W., Go, S.-J. \& Stackebrandt, E. (2006). Dyella yeojuensis sp. nov., isolated from greenhouse soil in Korea. Int J Syst Evol Microbiol 56, 2079-2082.

Lane, D. J. (1991). 16S/23S rRNA sequencing nucleic acid techniques in bacterial systematics. In Nucleic Acid Techniques in Bacterial Systematics, pp 115-175. Edited by E. Stackebrandt \& M. Goodfellow. New York: Wiley.

Lee, D. W. \& Lee, S. D. (2009). Dyella marensis sp. nov., isolated from cliff soil. Int J Syst Evol Microbiol 59, 1397-1400.

Ludwig, W., Strunk, O., Westram, R., Richter, L., Meier, H., Yadhukumar, Buchner, A., Lai, T., Steppi, S. \& other authors (2004). ARB: a software environment for sequence data. Nucleic Acids Res 32, 1363-1371.

Olsen, G. J., Matsuda, H., Hagström, R. \& Overbeek, R. (1994). fastDNAml: a tool for construction of phylogenetic trees of DNA sequences using maximum likelihood. Comput Appl Biosci 10, 41-48.

Pruesse, E., Quast, C., Knittel, K., Fuchs, B. M., Ludwig, W., Peplies, J. \& Glöckner, F. O. (2007). sILVA: a comprehensive online resource for quality checked and aligned ribosomal RNA sequence data compatible with ARB. Nucleic Acids Res 35, 7188-7196.

Weon, H.-Y., Anandham, R., Kim, B.-Y., Hong, S.-B., Jeon, Y.-A. \& Kwon, S.-W. (2009). Dyella soli sp. nov. and Dyella terrae sp. nov., isolated from soil. Int J Syst Evol Microbiol 59, 1685-1690.

Ziemke, F., Höfle, M. G., Lalucat, J. \& Rosselló-Mora, R. (1998). Reclassification of Shewanella putrefaciens Owen's genomic group II as Shewanella baltica sp. nov. Int J Syst Bacteriol 48, 179-186. 